\title{
Attitudes Towards the Use of Social Media as a Tool for Marketing \\ Sergio Gómez Molina
}

Researcher, Fundación Universitaria Católica del Norte (Colombia)

Lemy Bran Piedrahita

Research coordinator, Fundación Universitaria Católica del Norte (Colombia)

\section{Alejandro Valencia Arias \\ Adviser Fundación Universitaria Católica del Norte, Professor Instituto Tecnológico Metropolitano (Colombia) \\ Claudia Milena Arias Arciniegas}

Researcher, Fundación Universitaria Católica del Norte (Colombia)

Alejandro Silva Cortés

Researcher, Instituto Tecnológico Metropolitano (Colombia)

Rosa Velez Holguin

Researcher, Fundación Universitaria Católica del Norte (Colombia)

Doi: 10.1515/mjss-2017-0016

\begin{abstract}
The accelerated progress of Information and Communication Technologies (ICTS) has made that marketing strategies are strengthened through the construction, personalization and socialization of information, which is one of the main dynamic social media. The aim of this article is to identify the trends and evolution of attitudes towards the use of social media as a marketing tool. For this, a bibliometric analysis was developed, divided into two stages: obtaining information (database and search equation), and obtaining bibliometric indicators (quantity, quality and structure) between 2008 and 2016. Among the results it is observed that increasing topics are centered on: Consumer Attitude, Health, Advertizing, Communication y Consumer Behavior.
\end{abstract}

Keywords: social media; marketing; bibliometric analysis; attitudes

\section{Introduction}

The emergence of the internet causes a change in the way that humans communicate and relate (Bran et. al. 2017). The development of the Web and social networks, brought with them a change 
in the dimension of communications, where each user went from being a mere receiver of information, to becoming a creator (Maqueira \& Bruque, 2012; Hoyos \& Valencia, 2012; Arango, Gaviria \& Valencia, 2015), with these changes, the construction, personalization, and socialization of information became in the new dynamics of the use of social media (Blanco, Archila \& Ballesteros, 2016).

Nowadays, the reduction of connection costs, technological improvements and the massive arrival of personal computers to homes, schools, universities and companies, has favored that Internet and specifically social media are no longer seen as tools of leisure and recreation, to become an efficient instrument of work and study (Valencia, González \& Castañeda, 2016), mainly in the area of marketing. In recent years, it is observed an evolutionary dynamic in the scope of study object in marketing practices, going from isolated and sporadic transactions to the relations of exchange between organizations and their customers (Túñez, García \& Guevara, 2011)

For marketing theorists, Maqueira and Bruque, the origin of the internet has become in a new medium through which brands can establish closer relations with their customers. In addition, the constant dynamics of the evolution of social media have facilitated the emergence of new communication channels, which directly improve the reach and information transmission (RamírezVillamil y Puerta-Meza, 2016), narrowing the relationship between the target audience and the seller. For brands is evident that exist an increase marketing activities in social media, so they have begun to incorporate associated strategies, with the aim of making their products visible and improving their sales. The low cost of use, and the boom in popularity that these media currently have, makes their use inevitable to measure the reputation (Harris \& Rae, 2009) and satisfaction with their customers (Cartagena, Vásquez, Benjumea-Arias \& Valencia-Arias, 2017)

Attitudes towards the use of social media as a marketing tool emphasize in the use of social networks and refer to all those activities carried out in order to socialize, unveil and promote a brand through media such as Facebook, Twitter, YouTube, among others. The previously mentioned networks are the ones that have the greatest apogee among internet users, because they are the most recognized and most used given their ease of interaction between the consumer and the seller, through a personalization approach of the meeting (Pineda, Meneses \& Téllez, 2013; Bermudez, Chalela, Valencia \& Valencia, 2017). However, in this parallel universe of content generated by users, brands assume a fundamental role in interpreting the information shared by them, since in these channels they express enthusiasm about their favorite brand (Hennig et al., 2010), which gives organizations an alternative approach to their customer interaction plans. It is necessary to consider that not everything related to social media and marketing is positive, also to be exposed the information socialized by the user, problems can arise with the privacy and security of data, that is why the brands require a structural control of their media, or otherwise the credibility and value of the content may be disadvantaged (Otto \& Simon, 2008).

The new reality of the Internet has made the way to do marketing differently, that is to say, every marketing agent must be attentive to the evolutionary dynamics that are given in the media, and in that understanding of the new forms are social media. For this reason the present text seeks to examine the state of field of study on the attitudes toward the use of social media as a tool for marketing through a bibliometric analysis that shows academic production in the Scopus database between 2008 and 2016.

\section{Methodology}

This study was carried out using one of the most comprehensive and updated electronic databases, Scopus. In bibliometric analyzes, researchers can use any of the existing databases, because the validity of the research will depend largely on the selected database. The study is supported methodologically in some authors who understand that Scopus offers advantages over other databases. For example, the volume of literature available through Scopus is greater than that available through PubMed or WoS. In addition, Scopus offers dating analysis and a search engine friendly to users. (Falagas et al., 2008 cited in Sweileh, Al-Jabi, Sawalha, AbuTaha \& Sa'ed, 2016).

For the accomplishment of the bibliometric analyzes the search equation was defined according to the purpose of the study. For this, the search terms equivalent to social networks - 
social media. Likewise, terms related to marketing and attitude toward the use were also included in the search matrix in the title and keywords fields. Finally, 94 registers with the following search equation were obtained.

((TITLE (\{social media\} OR \{social network\})) OR KEY (\{social media\} OR \{social network\}) AND (TITLE (marketing) OR KEY (marketing)) AND (TITLE (attitud*) OR KEY (attitud*)))

From the field results, bibliometric indicators of quantity, quality and structure were calculated between 2008 and 2016, using Excel and free software CYTOSCAPE to calculate the respective networks.

\section{Analysis of results}

\subsection{Bibliometric indicators of quantity (productivity)}

Quantitative indicators are the ones that measure the productivity of a researcher, journal or institution in terms of the number of publications (Durieux \& Gevenois, 2010; Tan et al., 2009). Below, the quantity indicators corresponding to the field of attitudes towards the use of social media as a tool for marketing are presented.

\subsubsection{Scientific productivity in the knowledge field}

Figure 1 shows the scientific production between 2008 and 2016. In general, there is stability about the interest in the topic and an upward behavior of the registers in last 5 years. In 2014 the number of 21 articles was reached, one of the most outstanding authors that year was Hongwei Yang, with 5 published articles, this researcher works mass communication issues focused on advertising and currently he works as a professor in this subject, among his teaching specialties are: advertising and media planning, research methods in communication, strategic planning in advertising, professional ethics of international advertising and publicity. Some of his works focus attention on predicting people's attitudes to the perception of viral marketing; and to achieve these channels of information, establishes a methodology based on behavioral models that consider variables: (a) subjective norm, (b) perceived behavioral control, (c) perceived pleasure, and (d) market mavenism.

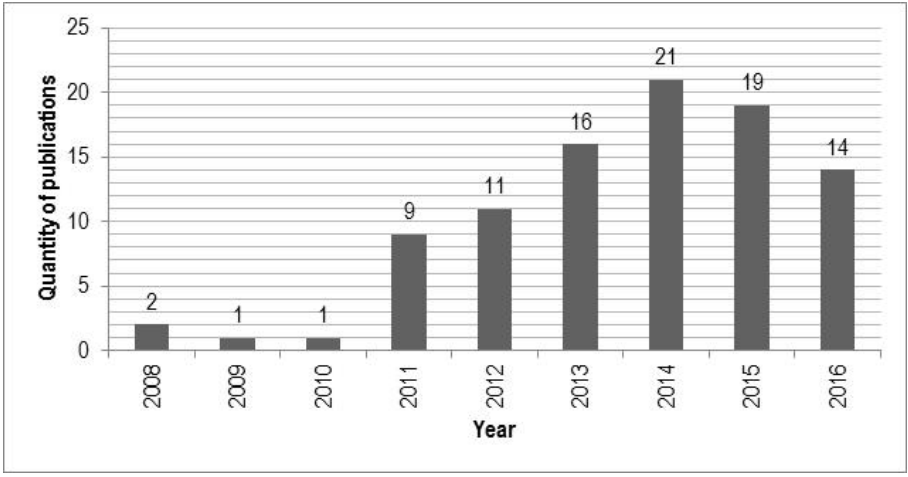

Figure 1. Publications per year. Prepared by the authors

It is important to emphasize that the first publications on this field investigate the determinants of brand satisfaction as a vital context for consumers to develop trust and brand loyalty (Lee \& Back, 2008). 


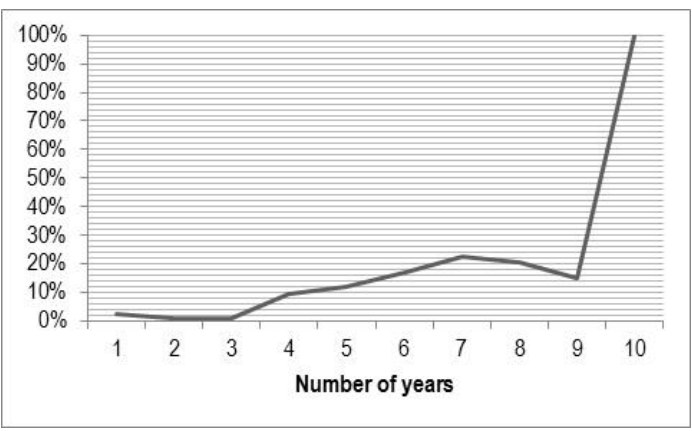

Figure 2. Percentage of publications accumulated per year. Prepared by the authors.

Figure 2 shows that field research has validated Price's exponential growth law, which states that scientific information grows at exponential rates, where every 10 to 15 years existing information is doubled (Fernández, Torralbo \& Vallejo, 2004). In this sense, it can infer that we are facing a discipline that is in the phase of exponential growth, in which not only the scientific literature increases but also the number of researches.

\subsubsection{Productivity of journals}

The most important journal in the field, in terms of its number of publications is Aesthetic Surgery Journal with 3 publications, followed by Computers In Human Behavior and International Journal Of Drug Policy. In Figure 3 shows the ten journals with the largest number of publications. With regard to journals' productivity, the cumulative percentage of publications per journal (see figure 4), reveals that there is no Pareto Law, since $76 \%$ of the journals published $80 \%$ of the articles, so the percentage of journals by level of importance (in quartiles) was separated, obtaining $12 \%$ of journals published $25 \%$ of articles, $39 \%$ of journals published $50 \%$ of articles and finally statistics showed that $70 \%$ of the journals published $75 \%$ of the articles. The information gathered shows that the distribution of articles by journal has an equitable distribution, since no single journal predominates for all registers exported by the database.

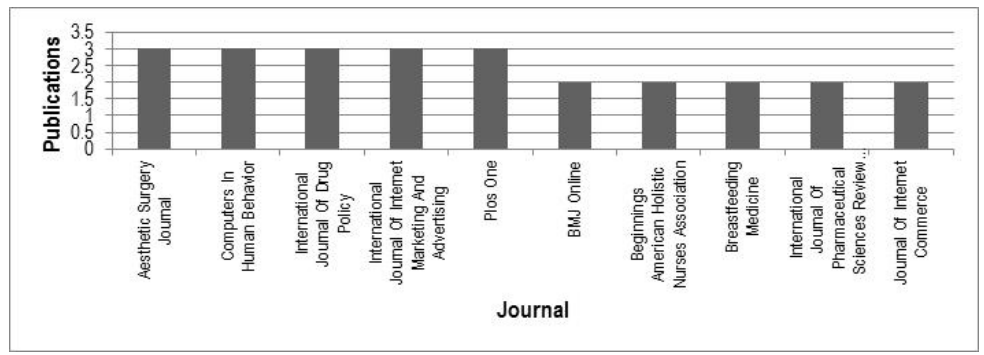

Figure 3. Most important journals in the field. Prepared by the authors.

\subsubsection{Productivity of the authors}

Figure 4 shows the existence of significant productivity of authors, and the presence of a not inconsiderable sample of authors who published between 1 and 2 articles, which could denote that for the field there are not a large number of temporary or occasional authors, on the contrary, there is a tendency to specialization in the profile of the study topic. This aspect is extremely favorable for the development and visibility of the field and may be influenced by the high presence of various international institutions. 


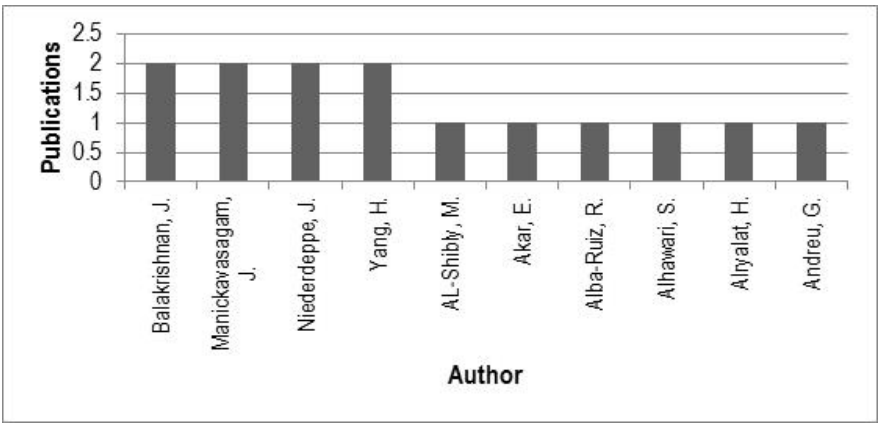

Figure 4. Main authors in the field. Prepared by the authors.

When the calculation of the ten most productive researchers on the topic was made, it was found that Janarthanan Balakrishnan along with 3 other authors top the list with 2 publications (see figure 3). A register of its activity appears from 2015 until 2016, according to registers exported by Scopus. One of the cited researcher's work focuses attention on how an individual's involvement in a particular product refers to the commitment or interest that a person has with that product based on their needs, values or interests, in addition to a relationship that underlies on beliefs, values, attitudes and behaviors toward social media ads (Natarajan, Balakrishnan, Balasubramanian \& Manickavasagam, 2015).

As in the journals, the productivity of the authors does not comply with Pareto law. Since, there are $80 \%$ of authors who published $80 \%$ of the total production. Given this situation, authors were separated by relevance (in quartiles), with $19 \%$ of authors published $25 \%$ of publications, $49 \%$ published $50 \%$ and $74 \%$ published $75 \%$. In this sense, as the quartile advances, there is a greater tendency for the percentage of publications to be proportional to the percentage of authors, proving that the distribution equivalent to one to one of articles per researcher, avoiding that publications of a single author in the literature.

\subsection{Bibliometric indicators of quality}

These indicators are commonly used to measure the frequency with which a publication, an author, or a journal, are cited by other publications (number of citations) (Durieux \& Gevenois, 2010). Below are presented the results obtained according to the search equation presented above.

\subsubsection{Impact by author}

With the quality indicators it is possible to find the ten authors with the greatest quantity of citations in the topic. In this sense, Neal Benowitz is the author with the largest number of citations, registering in the database an equivalent to 314 citations along with Stanton A. Glantz and Rachel Grana (see figure 5). It is also observed that no researcher on the list of authors with the greatest number of publications (see figure 4) appears in the list of the ten authors with the greatest impact, reflecting in this way that researchers with a high participation in the production of knowledge on the topic, are not enough to generate a great impact with their publications in the community and academic networks, which reflects an imbalance in the generation of knowledge and impact of the same. 


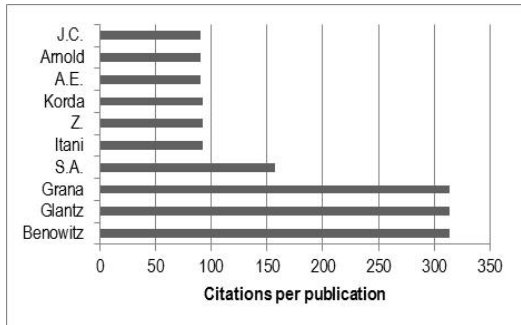

Figure 5. Authors with the greatest number of citations per publication. Prepared by the authors.

According to the Brand Community Model of Algesheimer et al. (2005 cited in Okazaki, Benito \& Martínez, 2012) the relationship of the consumer with the brand is established based on the identification with the brand community, which affects the user's commitment to the community. Identification with the brand community can be defined as "the strength of the relationship between the consumer and the brand community ... of which the person is considered a member." Commitment to the brand community refers to "the positive influences of identifying with the brand community, which are defined as the intrinsic motivations of interacting and cooperating with members of the community." A greater positive influence perceived by community users, is more likely for users to help each other, to participate in joint activities, and thus to interact in the community because they want it "so that the community strengthens and that increases their value for themselves and for other users". This study was able to validate that the Social Networks Model constitutes a fundamental tool when is examining and identifying factors, variables and relationships that inhibit or motivate the adoption processes and use of social networks as a useful tool in the processes or decision of purchasing.

Now, Social Networks are a global phenomenon, but only some platforms are dominating, such as Facebook, YouTube and Twitter, and more recently sites like Linkedln and Pinterest. Facebook, for example, has reached more than 1.1 billion active monthly users in eight years of being created, being today the largest in the world (Crunchbase, 2013 cited in Saavedra, Criado \& Andreu, 2013).

This is why the content of the publications with the greatest impact on the academic community are concentrated in the growth of the Social Networks activity, as a marketing strategy due to the low cost of use and its popularity, being used for the construction of brand and to measure the reputation of customer relationships (Harris \& Rae, 2009).

\subsubsection{Journal impact}

Figure 6 shows the ten most cited journals per publication in the field of social networks as a tool for marketing. The journal with the highest number of citations per publication has 314 and is Circulation, after this is Health Promotion Practice with 92 citations per publication. Compared with the most productive journals, the International Journal of Drug Policy (Impact: ninth, productivity: third), and Journal of Internet Commerce (impact and productivity: tenth) are the only ones that coincide on both lists, showing that through these, a high impact is achieved in the dissemination of knowledge of the field.

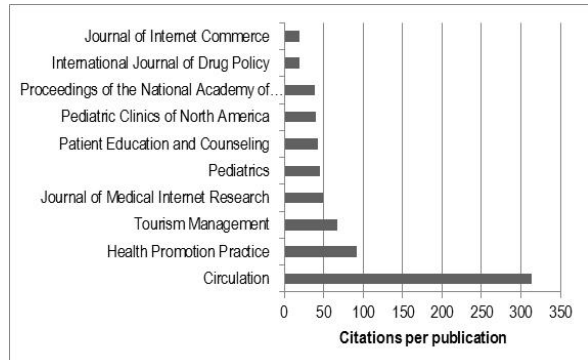

Figure 6. Journals'impact. Prepared by the authors. 


\subsubsection{Impact per year}

Finally, the bibliometric analysis allows identifying the years of greatest impact of the topic and it can be observed that the years with the highest number of citations per publication are between 2008 and 2014 (see figure 7). When is compared the impact per year with the annual productivity, the results obtained coincide since those years with greater impact present an adequate level of productivity.

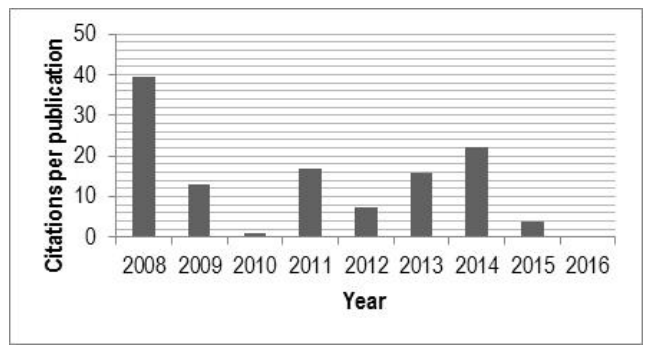

Figure 7. Impact per year. Prepared by the authors.

\subsection{Bibliometric indicators of structure}

Graphic 1 shows the network analysis in which the time window was fragmented according to the average proportion of the scientific production registered by Scopus database and two periods were obtained from that division, one between 2008-2012 and another between 2008-2016. In graphics 1 and 2 is presented the topological maps of the authors' network in the field of social networks as a tool of marketing.

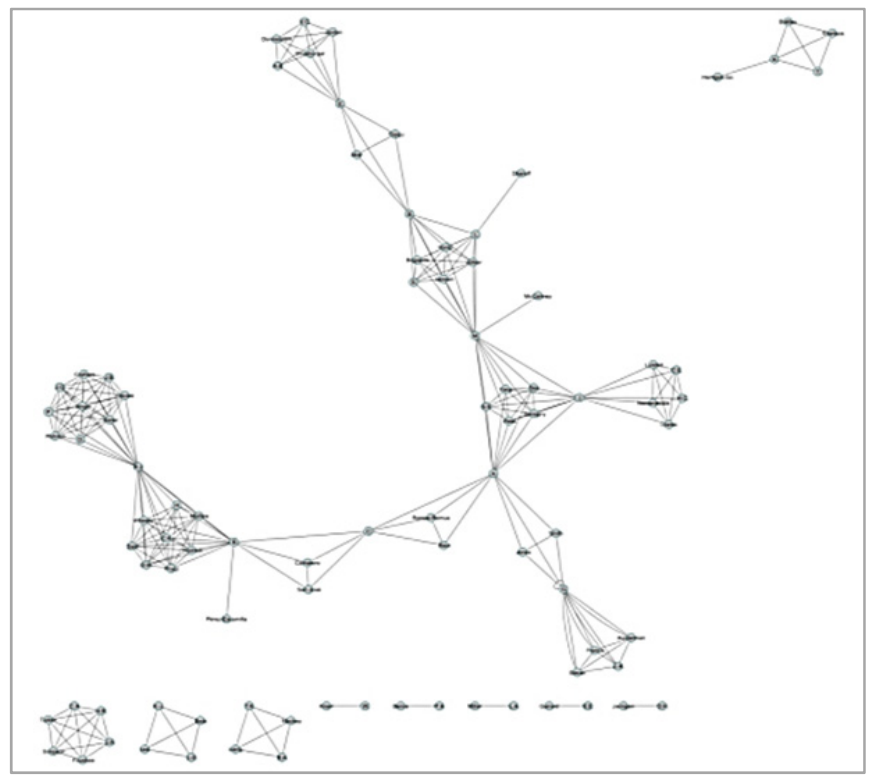

Graphic 1. Topological map of the authors' network in the field of Social networks as a tool for marketing between 2008-2012. Prepared by the authors. 


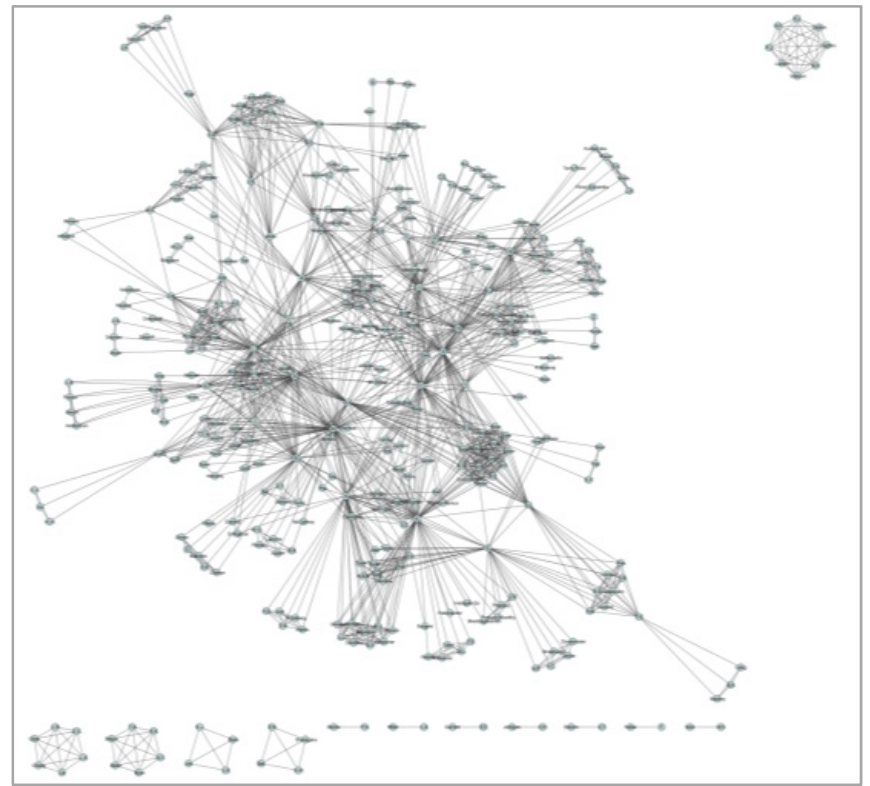

Graphic 2. Topological map of the authors' network in the field of social networks as a tool for marketing between 2008-2016. Prepared by the authors.

As shown in graphic 1 and graphic 2, researchers' network over the years show certain particularities and relevant characteristics, the indicator results about the authors' network are presented in the table 1, which shows that there are 358 authors and none of them publishes independently, and since the size of a network is very important, since it determines the structure of relationships (Fiscella \& Vásquez, 2008). The network presented by the authors of the field that considers the work that relates to the research centers is extensive, which shows that the researchers associated with the topic make a great effort to be able to participate with other experts of the network. On the other hand, the distance can be a good indicator of the size of the network $(2,888)$, since it is the parameter that indicates that the actors or nodes, on average, are intermediated by at least three nodes to relate to the rest of nodes in the network, another of the indicators that support the size of the network, is that referred to the average number of neighbors, and this shows that each author on average has published with 9 other authors $(8,855)$, confirming the considerable extension of the network.

Table 1. Structural indicators

\begin{tabular}{|l|c|c|}
\hline Indicator & $\mathbf{2 0 0 8 - 2 0 1 2}$ & $\mathbf{2 0 0 8 - 2 0 1 6}$ \\
\hline Number of nodes & 91 & 358 \\
\hline Network density & 0,062 & 0,025 \\
\hline Network diameter & 8 & 6 \\
\hline Characteristic density expected & 3,734 & 2,888 \\
\hline Number of components connected & 10 & 13 \\
\hline Average number of neighbors & 5,538 & 8,855 \\
\hline Grouping degree in the network (cluster) & 0,783 & 0,856 \\
\hline Network centralization & 0,142 & 0,175 \\
\hline Network heterogeneity & 0,623 & 1,082 \\
\hline Number of isolated nodes & 0 & 0 \\
\hline Components connected with nodes & $10,9 \%$ & $3,63 \%$ \\
\hline Components isolated with nodes & $0 \%$ & $0 \%$ \\
\hline
\end{tabular}


Added to this, the density of the network is close to zero (0.025), which shows the poor connectivity of some nodes in the network and that the potential connection between these authors is not being adequately exploited. However, this low connectivity is not a uniform property of the entire network. As shown in graphic 1 , there are certain zones with very high connectivity, which could indicate that the dispersion of production is significant, which is translated into an important centrality of some nodes, and for the contrary, the insufficient connection of others, consequently, a marked inequality to access or introduce information and knowledge in the network.

\section{Discussion of Growing and Emerging Issues Related to the Use of Social Media as a Tool for Marketing}

For the elaboration of this analysis the frequency of the keywords of the 94 articles related to the use of social media as a tool for marketing was taken as reference, in this one the key words most used in the articles used in the bibliometric analysis, initially the 8 with the greatest number of use were identified and are shown in figure 8.

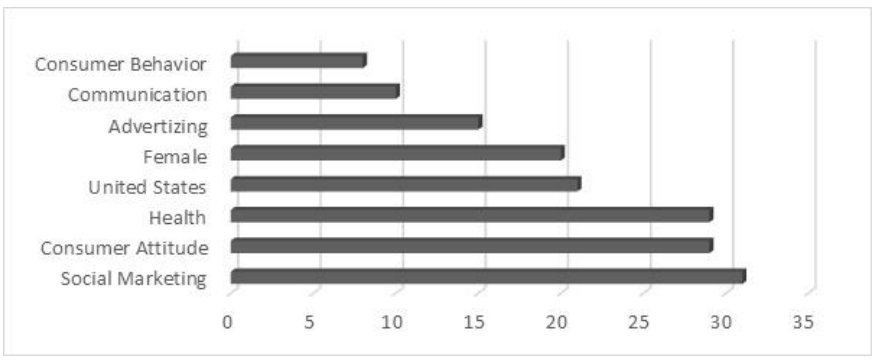

Figure 8. Main emerging topics

In the consolidation of research field, there are strategic points that stand out, the present analysis weighs the followings:

\subsection{Social Marketing}

From the social marketing dimension, the thematic approach has incorporated, among other things, social marketing and the tendency of implication on the application of commercial marketing principles in order to promote the success in sales. Social marketing requires much more than communication campaigns that involves social networks (Hemsley \& Dann, 2015), as Saavedra \& Rialp suggest, the experiences of the emerging and growing phenomenon of the use of social networks directly favor the financial benefits of brands, even the incorporation of social marketing can be done with the support of specialized companies in the development of strategies of this type. One of the alternatives of social marketing is to direct campaigns to influential social forces such as families, specific service providers and legislators, as they are niches that affect the decision-making capacity and impact on population groups (Escamilla, 2012).

On the other hand, social marketing becomes a tool for organizations to favor changes of behaviors, attitudes, ideas and collective imaginaries that are assumed to be harmful for society, so some authors claim that social marketing becomes a tool for people to internalize new behaviors (Aristizábal, Restrepo \& Arias, 2007).

\subsection{Consumer Attitude}

Regarding the consumer's attitude, John R. Hamilton suggests that consumer interpretation in social networks involves, in addition to consumer motivation, a planned behavior related to the psychology of the individual, and in that value judgment is weighted the consumer behavior cycle 
before, during and after the event of involvement between brand and individual (Akar \& Topcu, 2011).

Similarly, studies have been carried out on the use of new platforms that reconfigure consumer attitudes, such as the use of micro blogs as an emerging alternative to e-commerce (Ren Bao \& Shanygina, 2013). In turn, sellers interpret channels of impact on users, Jain \& Reed, propose that consumers assign weighting to the information they receive depending on the medium and the channel in which they arrive, hence the importance of the latter on the attitude of themselves in relation to the marketing process (Jain \& Reed, 2013).

\subsection{Health}

Social media and digital marketing are beginning to become a key tool for the effective development of the health dimension, for Luis Ramiro Beltrán, the systematic use of strategies and instruments provided by social media favors the achievement of program objectives proposed by the institutions. At the same time the use of social media constitutes an emerging dynamics of disease prevention and health promotion, an example of this is demonstrated by Frerichs in his research, where it is evident that health promotion for the prevention of obesity through social networks favors health conditions of the population and enriches the processes of community mobilization (Frerichs, Sjolie, Curtis, et al, 2015).

Some studies have focused on studying the opinions of health professionals, organizations and users regarding the trends of action between services and social networks, and conclude that it is necessary to move forward and to commit to increase the communication channels of social media to better respond in the provision of services (Koumpouros, Toulias \& Koumpouros, 2015).

However, social media are also related to the health dimension as they drive new business models, the channels of communication offered by social media favor the understanding of the emotions, feelings and perceptions of consumers, as well as the use of social media provides support information to understand user behavior (Thomas \& Woodside, 2016), the use of social media can be an important tool for institutions in charge of managing resources in the area of Health, improve levels of interaction with clients, and also, service coverage indicators are impacted as social media reach a greater number of people.

\section{Conclusions}

The main reason for performing the bibliometric analysis was to identify the knowledge field state about attitudes towards the use of social media as a tool for marketing, its evolution achieved and its tendency to continue developing in the coming years. It was possible to identify that this has been a little mentioned topic in the literature during the years 2010, 2012 and 2016. Additionally this work contributes to researchers in the field, since no reference of similar analyzes in the topic was found.

It was verified that the study of this topic has had an exponential growth according to Price's law since 2008, where the window of observation of this analysis began. It is observed that between 2013 and 2015 the topic was becoming important for the researchers, favoring the exchange of knowledge and collaboration between authors, as shown in the connectivity of the nodes, some with a high concentration, allowing the extension of the network of knowledge among researchers.

On the other hand, the authors with the greatest number of publications do not appear in the list of researchers with the highest number of citations per publication, evidencing a low correlation between quantity and impact of researchers in the topic.

The analysis shows that the world-wide leadership in this topic, in terms of publications, has two developed and one emerging countries, led by the United States, United Kingdom and India, English being the predominant language in publications.

Faced with this situation, the bibliometric analysis allowed to present a trend of how the field of study is and show the possibilities that exist to enrich this area of knowledge, which made it possible to visualize aspects such as: the amount of literature available, researchers interested in the topic and the quality of the publications in this topic. 


\section{References}

Akar, E., \& Topçu, B. (2011). An examination of the factors influencing consumers' attitudes toward social media marketing. Journal of Internet Commerce, 10(1), 35-67.

Aristizábal Botero, C. A., Restrepo Múnera, M. L., \& Arias Pérez, J. E. (2007). Impactos del mercadeo social en organizaciones de servicios. Semestre económico, 10(19), 113-123.

Bao, X. R., \& Shanygina, D. N. (2013). The Impact of Microblog Marketing on Consumer Attitude and Behavior. In Applied Mechanics and Materials (Vol. 427, pp. 2656-2659). Trans Tech Publications.

Bermudez, J., Chalela, S., Valencia, J. \& Valencia, A. (2017). Research Trends in the Study of ICT Based Learning Communities: A Bibliometric Analysis. EURASIA Journal of Mathematics, Science \& Technology Education. 13(5), 1539-1562. DOI: 10.12973/eurasia.2017.00684a

Blanco, T., Archila, D. M., \& Ballesteros, J. A. (2016). Gestión de datos obtenidos desde redes sociales aplicando Business Intelligence Engineering Process. Revista Virtual Universidad Católica del Norte, (49), 72-91.

Bran, L.; Romero, K.; Echeverri, L.; Peña, J.; Vasquez, S.; Aguilera, M.; Herazo, C. y Valencia, A. (2017). Information and Communication Technologies Influence on Family Relationship. Global Journal of Health Science, 9(6), 204-213. DOI:10.5539/gjhs.v9n6p204

Cartagena, C., Vásquez, A., Benjumea-Arias, M., \& Valencia-Arias, A. (2017). Proposed Model for Measuring Customer Satisfaction with Telecommunications Services. Mediterranean Journal of Social Sciences 8(2), 15-26, 2017. DOI: 10.5901/mjss.2017.v8n2p15

Durieux, V., \& Gevenois, P. A. (2010). Bibliometric indicators: Quality measurements of scientific publication. Radiology, 255(2), 342-351.

Fiscella, J. M. G., \& Vásquez, J. I. (2008). Conocimiento y estructura en la investigación académica: una aproximación desde el análisis de redes sociales. Redes. Revista hispana para el análisis de redes sociales, 14

Frerichs, L., Sjolie, S., Curtis, M., Peterson, M., \& Huang, T. T. K. (2015). Process and Outcomes from a YouthLed Campaign to Address Healthy Eating in an Urban High School. The journal of primary prevention, 36(6), 433-438.

Harris, L. and Rae, A. (2009). Social networks: The future of marketing for small business. The Journal of Business Strategy, 30(5), 24-31

Hemsley, B. \& Dann, S. (2014). Social media and social marketing in relation to facilitated communication: Harnessing the affordances of social media for knowledge translation. Evidence-Based Communication Assessment and Intervention, 8(4), 187-206.

Hennig-Thurau, T., Malthouse, E. C., Friege, C., Gensler, S., Lobschat, L., Rangaswamy, A., \& Skiera, B. (2010). The Impact of New Media on Customer Relationships. Journal of Service Research, 13(3), 311330. DOI: $10.1177 / 1094670510375460$

Hoyos, J. \& Valencia, A. (2012). El papel de las TIC en el entorno organizacional de las pymes. Trilogía. Ciencia, Tecnología y Sociedad. 7(1), 105-122

Jain, Y., \& Reed, D. (2013). DMA print tracking: Attributes of media channels. Journal of Direct, Data and Digital Marketing Practice, 15(1), 56-63.

Koumpouros, Y., Toulias, T. L., \& Koumpouros, N. (2015). The importance of patient engagement and the use of Social Media marketing in healthcare. Technology and Health Care, 23(4), 495-507.

Lee, J. S., \& Back, K. J. (2008). Attendee-based brand equity. Tourism Management, 29(2), 331-344.

Maqueira, J y Bruque, S (2012). Marketing 2.0. El nuevo marketing en la Web de las Redes Sociales. México: AlfaOmega

Natarajan, T., Balakrishnan, J., Balasubramanian, S. A., \& Manickavasagam, J. (2015). Examining beliefs, values and attitudes towards social media advertisements: results from India. International Journal of Business Information Systems, 20(4), 427-454.

Okazaki, S., Benito, N. R., \& Martínez, S. C. (2012). Antecedentes de las redes sociales como canales de comunicación promocional para los jóvenes. Revista Española de Investigación en Marketing ESIC, 16(2), 31-48.

Otto, P. and Simon, M. (2008). Dynamic perspectives on social characteristics and sustainability in online community networks. System Dynamics Review, 24(3), 321-347.

Pérez-Escamilla, R. (2012). Breastfeeding social marketing: lessons learned from USDA's "Loving Support" campaign. Breastfeeding Medicine, 7(5), 358-363.

Pineda, E., Meneses, T., \& Téllez, F. R. (2013). Análisis de redes sociales y comunidades virtuales de aprendizaje. Antecedentes y perspectivas. Revista Virtual Universidad Católica del Norte, 1(38), 40-55.

Ramírez-Villamil, C. O., \& Puerta-Meza, K. L. (2016). Identificación de factores motivantes de compra en tiendas universitarias: el caso de la Universidad Nacional de Colombia-sede Medellín. Revista CEA, 2(4), 89-99. 
Saavedra, F. U., Criado, J. R., \& Andreu, J. L. (2013). El uso de las redes sociales digitales como herramienta de marketing en el desempeño empresarial. Cuadernos de administración, 26(47), 205-232.

Thomas, L., \& Woodside, J. M. (2016). Social media maturity model. International Journal of Healthcare Management, 9(1), 67-73.

Túñez, M., García, J. S., \& Guevara, M. (2011). Social networks and viral marketing: repercussion and incidence in the construction of the media agenda. Palabra Clave, 14(1), 53-65.

Valencia, A., González, G \& Castañeda, M. (2016). Structural equation model for studying the mobile-learning acceptance. IEEE Latin America Transactions. 14(4), 1988-1992. DOI: 10.1109/TLA.2016.7483544

Valencia, A., Salazar, O. \& Ovalle, D. (2013). Improving the Entrepreneur's Market Research Strategies Learning Process Using the MaREMAS Environment”. En: Highlights on Practical Applications of Agents and Multi-Agent Systems. Springer Berlin Heidelberg, 363-374. DOI: 10.1007/978-3-642-38061-7_34

Yang, H. (2013). A cross-cultural study of market mavenism in social media: exploring young American and Chinese consumers' viral marketing attitudes, eWOM motives and behaviour. International Journal of Internet Marketing and Advertising, 8(2), 102-124. 